\title{
Article
}

\section{In pursuit of sustainable co-authorship practices in doctoral supervision: addressing the challenges of writing, authorial identity and integrity}

Lokhtina, Irina, Löfström, Erika, Corner, Solveig and Castello, Montserrat

Available at http://clok.uclan.ac.uk/34144/

Lokhtina, Irina ORCID: 0000-0001-5223-3779, Löfström, Erika, Corner, Solveig and Castello, Montserrat (2022) In pursuit of sustainable co-authorship practices in doctoral supervision: addressing the challenges of writing, authorial identity and integrity. Innovations in Education and Teaching International, 59 (1). pp. 82-92. ISSN 1470-3297

It is advisable to refer to the publisher's version if you intend to cite from the work. http://dx.doi.org/10.1080/14703297.2020.1799839

For more information about UCLan's research in this area go to http://www.uclan.ac.uk/researchgroups/ and search for < name of research Group>.

For information about Research generally at UCLan please go to http://www.uclan.ac.uk/research/

All outputs in CLoK are protected by Intellectual Property Rights law, including Copyright law. Copyright, IPR and Moral Rights for the works on this site are retained by the individual authors and/or other copyright owners. Terms and conditions for use of this material are defined in the policies page. 


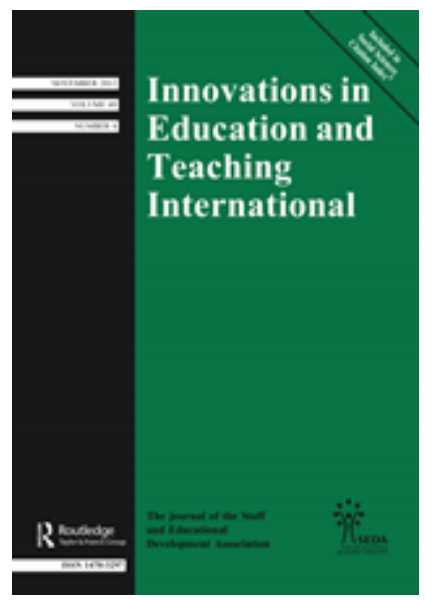

In pursuit of sustainable co-authorship practices in doctoral supervision: addressing the challenges of writing, authorial identity and integrity

\begin{tabular}{|r|l|}
\hline Journal: & Innovations in Education and Teaching International \\
\hline Manuscript ID & RIIE-2019-0301.R3 \\
\hline Manuscript Type: & Original Article \\
\hline Areas of Interest: Keywords: & co-authorship, supervision, doctoral students, identity, integrity \\
\hline \multicolumn{2}{|l}{} \\
\hline
\end{tabular}

\section{SCHOLARONE" \\ Manuscripts}




\title{
In pursuit of sustainable co-authorship practices in doctoral supervision: addressing the challenges of writing, authorial identity and integrity.
}

\begin{abstract}
Developing an authorial voice along with co-authorship practices can be an important pathway towards building one's professional identity and career. However, challenges may arise when contributors have different expectations about co-authorship conventions and are accountable to different stakeholders. This article aims to explore co-authorship practices between doctoral students and supervisors by drawing on four dimensions that highlight professional challenges across disciplinary and national contexts: 1) supervisors' writing and co-authorship, 2) strategies and activities to support writing, 3) authorial voice, and 4) integrity and (the risk of) plagiarism. The article summarises practices and suggestions for academics and policymakers on how to create and promote an ethical and sustainable approach to co-authorship in supervisory context.
\end{abstract}

Keywords: co-authorship, supervision, doctoral students, identity, integrity 


\section{Introduction}

An understanding of co-authorship practices develops during doctoral studies, and writing collaborations between doctoral students and supervisors has become an important pathway towards building one's academic identity and professional record (Kamler, 2008). Indeed, in academia today, it is virtually impossible for researchers to operate without scientific collaboration (Henriksen, 2016) and co-authoring (Acedo et al., 2006). Co-authorship between doctoral students and supervisors has become increasingly relevant through the tendency in many institutions to encourage article-based doctoral dissertations.

While authorship attribution is an increasingly important 'currency' of academia (Macfarlane, 2017), it is not only a reward but also a responsibility of participating authors (Smith, 2017) that involves establishing and maintaining effective communication, agreeing on work expectations and meeting deadlines (Conn et al., 2015). These often depend on the nature of collaborative relationships between doctoral students and supervisors, as well as on their approach to managing authorship.

A growing number of studies explore the grounds for co-authorship (Cutas \& Shaw, 2015; Leane et al., 2019; Selbach et al., 2018). With this article, we wish to build specifically on research addressing challenges in co-authorship among doctoral students and supervisors (cf. Kamler, 2008). This article presents a synthesis of the central perspectives on coauthorship in a supervisory context that each of us has identified from our interdisciplinary research areas, including writing, ethics, well-being and academic identity. We recognise that the four dimensions we have chosen, though highlighted by research as crucial, are not exclusive, and other disciplinary approaches may identify other challenges and solutions as well. Rather than an ad hoc combination of existing literature, this synthesis based on the collected findings from the authors' recent research is an attempt to take part in the discussion on writing in doctoral education in an era of 'publish or perish' discourse (cf. McGrail, 2006). In doing so, we emphasised the importance of considering the four sustainable practices, so co-authorship in supervisory context could become a much more fulfilling experience for all concerned in different disciplinary and national context.

The synthesis is based on literature reviews and results presented in our research on writing, authorial voice (Castelló \& Donahue, 2012; Castelló et al., 2013; Nelson \& Castelló, 2011; James \& Lokhtina, 2018) and integrity (Löfström \& Pyhältö, 2012; 2014; 2015; Löfström et al., 2015; Löfström et al., 2017). The article does not present a literature review per se, but the reader is referred to the above-mentioned studies. Moreover, we wish to 
explicitly acknowledge the importance of the work of Kitchener (1985, referred to in Löfström \& Pyhältö, 2012; 2014; 2015), East (2010), Valentine (2006, referred to in Löfström et al., 2015) and McAlpine \& Amundsen (2009, referred to in James \& Lokhtina, 2018) for our prior research. Here we bring together what we have identified, based on the studies listed above, to be relevant dimensions of co-authorship in the context of supervision in doctoral studies, and elaborate on those dimensions. While many practices around both supervision and co-authorship are contextual and field-specific, we aggregated the four dimensions of the writing process that are of interest across disciplinary and national contexts, consisting of:

1) supervisors' writing and co-authorship, (González-Ocampo \& Castelló, 2018; Inouye \& McAlpine, 2019);

2) strategies and activities to support writing (Castelló \& Donahue, 2012; Castelló et al., 2013; Castelló et al., 2017; Florence \& Yore, 2004);

3) authorial voice (Nelson \& Castelló, 2011; McAlpine \& Amundsen, 2009; James \& Lokhtina, 2018); and

4) integrity and (the risk of) plagiarism (Löfström \& Pyhältö, 2012, 2014, 2015; Löfström et al., 2015; Löfström, et al., 2017).

We conclude by summarising practices and suggestions for academics and policymakers on how to create and promote an ethical and sustainable approach to coauthorship in a supervisory context.

\section{Supervisors' writing and co-authorship}

Whereas research on doctoral students' writing has been extensive and growing over the last two decades (Caffarella \& Barnett, 2000; Carlino, 2012; Castelló et al., 2009b; Castelló et al., 2013; Inouye \& McAlpine, 2019; Kamler, 2008; Kamler \& Thomson, 2014), studies focusing on supervisors' writing and even on faculty or experienced researchers' writing have been scarce (Florence \& Yore, 2004; Iñesta \& Castelló, 2012). Yet, in discussing co-authorship practices between students and supervisors, it is important to understand supervisors' writing experiences and expectations. The evidence from studies that focus on this area sheds light on three complementary aspects.

Firstly, writing difficulties do not disappear after doctoral graduation and even experienced researchers struggle with writing, specifically to adjust different genres to their 
disciplinary discourses (Emerson, 2012; Iñesta \& Castelló, 2012; Tardy, 2003; Swales, 2009). What is different from students' perspective is how supervisors tend to deal with the challenges and make strategic use of their knowledge and rhetorical strategies to position themselves as authors in the scientific community (Iñesta \& Castelló, 2012; Florence \& Yore, 2004).

Secondly, there is some evidence regarding how perceived competence, attitudes and especially feelings towards writing mediate or interfere with researchers' genre preferences. Those researchers that consider writing as a demanding but also rewarding activity are more able to engage in research and scientific writing than those who perceive research writing as non-relevant or unsatisfactory (Bazerman et al., 2012; Gallego et al., 2016).

Thirdly, highly productive researchers and writers tend to be active members in their disciplinary and scientific communities and demonstrate deep knowledge not only of the rhetorical requirements of written genres, but also of the research field-related dynamics and social relationships among authors. This knowledge is demonstrated through their strategic decisions regarding how to write and interact with other authors through citations, peer revision processes and journal selection and publication (Dressen-Hammouda, 2008; Emerson, 2012).

Research supports the idea of writing as a developmental process related to researchrelated competences and identity development (e.g. Ivanic 2005; Castelló, et al., 2017; Inouye \& McAlpine, 2019), that requires emotional engagement (Aitchison et al., 2012) and is socially situated (Prior, 2013; Castelló, et al., 2017; Iñesta \& Castelló, 2012). At the same time, in a collaborative context, this process is filtered and influenced by the supervisors' writing habits, prior experiences and strategies, as well as their position within the discipline or research area.

\section{Strategies and activities to support writing}

Research on how supervisors support writing has mainly focused on the identification and analysis of the supervisory strategies to support student writing and on how these strategies and other types of writing feedback are perceived both by students and, to a lesser extent, supervisors. More recently, the impact of supervisory writing support strategies and feedback on students' development and learning as writers and researchers has been also investigated. 
Research on supervisory feedback on writing has revealed that supervisors are often unaware of the particular challenges that their students experience when having to write in unfamiliar genres, such as articles or doctoral dissertations, as well as the difficulties they face in publishing their research (Caffarella \& Barnett, 2000; Bitchener et al., 2010; Maher et al., 2014). Studies have repeatedly demonstrated that a high number of doctoral students and even postdocs hold maladaptive conceptions about writing that may result in them procrastinating and experiencing writing blocks, especially if they are perfectionists (Lonka et al., 2014; Cerrato-Lara et al., 2017; Castelló et al., 2017). However, students' challenges as writers are quite unknown to supervisors. There is abundant evidence from research, but also from supervisory daily work and training, that highlights supervisors' concerns when they realise that students are apparently unable to learn simply from text corrections or that they do not just write and submit their texts in due time (Lee \& Murray, 2015). While supervisors may believe that they contribute substantially to the students' writing process as well as learning process, the students might, at the end of the day, find themselves struggling alone to understand the genre, the expectations and the nature of relationships formed around the writing.

Subsequently, supervisors offer different types of writing support to help their students to deal with their writing difficulties. In a recent study, González-Ocampo \& Castelló (2018) identified three categories of writing support that varied in terms of supervisors' involvement. The first category consisted of telling the students what to do, how they should write and what good research texts and genres look like (e.g. offering them good models). Supervisors representing the second category usually reviewed and edited students' texts, since, as experienced writers, they are supposed to know and manage genre conventions. In these cases, supervisors hope explicit corrections would be enough for their students to learn to deal with these conventions and their dynamics when facing particular writing situations. The third category consisted of a group of supervisors who were concerned about teaching research writing to their students and thus tended to write and discuss texts collaboratively with their students. Moreover, research has repeatedly demonstrated that the different types of writing support that supervisors are able to offer relate to their own conceptions on how writing works and the role that they attribute to writing in their activity as researchers (Coterall, 2011; Lee \& Murray, 2015; González-Ocampo \& Castelló, 2018).

Available evidence on the impact of different supervisory support strategies on students' writing, although limited, points in the same direction. Strategies that involve supervisors and students at different levels of collaborative writing have been found to be 
useful not only in developing efficient and effective writers, but also in contributing to the students' knowledge of their respective disciplinary research communities. These strategies account for the social dimension of writing, in many cases unknown to the students, and can be promoted not only through the supervisors' explicit and contingent comments throughout the writing processes, but also by involving other researchers with different levels of experience and with different roles in the process of planning, writing, revising and publishing (Aitchison \& Guerin, 2014; Guerin et al., 2017; Florence \& Yore, 2004; González-Ocampo \& Castelló, 2018, Lee \& Murray, 2015; Paré, 2011; Kamler, 2008). Thus, in relation to the doctoral students' writing process, supervisors may take a number of decisions, make suggestions and initiate supportive steps in certain directions, but the underlying justifications and the aims of these activities remain implicit and non-transparent to the students.

\section{Supporting authorial voice}

Despite the nature of supervisory support for writing, which is often implicitly assumed, the choice of writing strategies for constructing academic texts exemplifies how doctoral students engage in dialogue with the discourses and establish connections with other authors' texts (Ivanic, 2005). These connections may encompass formal rules that provide some sort of order associated with authority and authenticity in academic writing (Nelson \& Castelló, 2011).

Whereas academic writing conventions seem to be relatively invariant across European countries (Kruse et al., 2016), there might be tensions between dominant supervisory writing strategies and the expectations of doctoral students about the writing, which may influence students' authorial identity. Authorial identity as a facet of academic identity may exemplify academics' authorial voice (Inouye \& McAlpine, 2019; McAlpine \& Amundsen, 2009), which is mediated by the text (Castelló et al., 2009b).

It is thus not surprising that writing an academic text as an ongoing, object-directed and dialectically-structured activity (Russell, 1997) may involve asymmetric relations between gatekeepers and 'less powerful' academics (Burrough-Boenish, 2003). In such circumstances, doctoral students can continually negotiate their authorial voice as they engage in their respective disciplinary communities (Castelló et al., 2009a). These 
negotiations can variously influence the textual choices made by doctoral students, who may retain partial ownership over their writing strategy. This highlights how authorship and writing practices can be complex and present challenges for doctoral students in determining how they see themselves and are perceived by others within their disciplinary communities (James \& Lokhtina, 2018).

Hence, with regard to doctoral students' writing practices, education interventions concerning writing in groups (e.g. among doctoral students or with supervisors) may provide them with access to legitimate participation within communities in which doctoral students may claim membership. From an educational perspective, such formally structured activities and engaging in dialogue about them can be viewed as a tool to help doctoral students to increase their awareness of different voices and other authors' contributions to the text, as well as a way to learn to negotiate their authorial voice and academic identity.

\section{Integrity and dealing with (the risk of) plagiarism}

While co-authorship provides a space for negotiating the individual authorial voice, the voice also stands in relation to "other voices". It is important, even at an early stage, to openly discuss principles of co-authorship, e.g. who is an author and author order (Hakkarainen et al., 2014; Johansen et al., 2019). Challenges and problems arise when contributors have different expectations about co-authorship conventions. One of the major problems that arise in the case of multiple authors is inappropriately assigning authorship credit or failure to assign credit when due, giving a false impression of the true contribution (Macfarlane, 2017). Supervisors sometimes struggle with how extensive a contribution they should make to student articles for these to still be considered the students' work (Löfström \& Pyhältö, 2012). In contrast, doctoral students may be perplexed by what counts as a sufficient contribution by the supervisor (Löfström \& Pyhältö, 2015).

Plagiarism may constitute another challenge for co-authorship. Codes of conduct for researchers define plagiarism as research misconduct along with falsification and fabrication (e.g. ALLEA, 2017). Yet, many authors view plagiarism as a developmental issue, or an issue arising from cultural and ideological differences, or simply different expectations rather than a moral transgression per se (e.g. Pecorari, 2003; Hayes \& Introna, 2005; Angelil-Carter, 2005; Valentine, 2006; Abasi \& Graves, 2008; East, 2010). Individual supervisors may 
represent different takes on this question, and their stance is likely to influence their supervision practices (e.g. Löfström et al., 2015).

The responsibility for the integrity of the work presented in a publication extends to all authors (e.g. the Vancouver Protocol, ICMJE), and the fact that supervisors are responsible as co-authors of the writing they publish together with their doctoral students may cause some supervisors to be cautious in co-authoring with their supervisees. However, supervisors can also be guilty of plagiarising the writing of their doctoral students (cf. Löfström \& Pyhältö, 2014). The expanding use of text-matching software is changing the landscape of supervision and writing (Löfström et al., 2017). It may add a safeguard against plagiarism, but it may also signal distrust towards doctoral students.

\section{Co-authorship practices: The future}

This article has explored co-authorship by drawing on four dimensions of the writing process and identified a number of challenges that both doctoral students and supervisors may experience in different disciplinary and national contexts. Key challenges and sustainable coauthorship practices that can address these challenges include:

\section{Helping supervisors to support early career researchers' writing development}

We identified the idea of writing as a developmental process related to research competences and identity development as a challenge in supervisors' writing and co-authorship. We further identified the supervisors' own conceptions on how writing works and the role they attribute to writing in their activity as researchers to be a challenge in connection to strategies and activities to support doctoral students' writing.

\section{Supporting doctoral students in adopting a long-term developmental diversified} approach to writing

Learning to write in academic genres requires a sense of self as a writer. Writing retreats for doctoral students may offer opportunities not only for writing but also for reflecting on their writing strategies. As supervisors' writing practices may shape their supervisory practices, supervisors may benefit from opportunities to reflect on writing and authorship, some of which might take place together with doctoral students.

\section{Helping students to develop and support their own voice in writing}


We identified the importance of raising awareness among doctoral students of the authorial identity that they project in their own writing. It may be important for doctoral students to be involved in writing communities. This may help them to grasp the nature of the educational relationship in which they engage with supervisors and fellow students. In doing so, doctoral students may have an opportunity to explore collaborative writing approaches and to understand how their participation in writing communities may help them negotiate issues of co-authorship and support their own voice and identity (cf. Aitchison \& Guerin, 2014; Lokhtina, 2018).

\section{Strengthening integrity and trust}

In order to preserve trust, it is vital that the practices employed are transparent and protect the rights of both doctoral students and supervisors (Hakkarainen et al., 2014). Most recognised journals nowadays use text-matching software to ensure the originality of the work they publish. It may be important for doctoral students to learn that everybody's writing is subjected to the same procedure in the publication phase, irrespective of academic rank and position. Guidelines for authorship and identifying when and how to negotiate it (e.g. Finnish National Board on Research Integrity, 2018; ICMJE, 2018) provide a basis for both supervisors and doctoral students to negotiate co-authorship on equal grounds.

While higher education institutions are keen on increasing scientific publication output, institutional support for doctoral students in developing their authorial voice and strengthening solid practices for authorship and co-authorship may not be the primary targets of investments. A discourse of 'publishing or perishing' permeates much of academia (McGrail et al., 2006) but we do not identify a similarly powerful discourse relating to sustainable writing practices, authorial voice or integrity. Therefore, we hope that this synthesis serves to instil an alternative discourse about writing with focus on development of authorial voice, support, and integrity. Development of resources and programmes to realise these important aspects of writing may require reconsideration of the role and practices of writing as well as institutional support mechanisms. Increasing support for doctoral students in navigating authorial identity and integrity alongside writing instruction is bound to strengthen writing communities in the long run.

\section{References}


Abasi, A. R., \& Graves, B. (2008). Academic literacy and plagiarism: Conversations with international graduate students and disciplinary professors. Journal of English for Academic Purposes, 7(4), 221-233.

Acedo, F. G., Barroso, C., Casanueva, C., \& Galán, J. L. (2016). Co-Authorship in management and organisational studies: An empirical and network analysis. Journal of Management Studies, 43(5), 957-983.

Aitchison, C., \& Guerin, C. (Eds.) (2014). Writing groups for doctoral education and beyond: Innovations in practice and theory. Routledge.

Aitchison, C., Catterall, J., Ross, P., \& Burgin, S. (2012). 'Tough love and tears': Learning doctoral writing in the sciences. Higher Education Research \& Development, 31(4), 435-447.

ALLEA (2017). European code of conduct for research integrity. Revised edition. http://www.allea.org/wp-content/uploads/2017/04/ALLEA-European-Code-ofConduct-for-Research-Integrity-2017.pdf.

Angelil-Carter, S. (2000). Stolen language?: Plagiarism in writing. Pearson Education.

Bazerman, C., Keranen, N., \& Encinas, F. (2012). Facilitated immersion at a distance in second language scientific writing. In M. Castelló \& C. Donahue (Eds.), University writing: Selves and texts in academic societies (pp.235-248). Brill.

Bitchener, J., Basturkmen, H., \& East, M. (2010). The focus of supervisor written feedback to thesis/dissertation students. International Journal of English Studies, 10(2), 79-97.

Burrough-Boenish, J. (2003). Shapers of published NNS research articles. Journal of Second Language Writing, 12(3), 223-243.

Caffarella, R., \& Barnett, B. (2000). Teaching doctoral students to become scholarly writers: The importance of giving and receiving critiques. Studies in Higher Education, 25(1), 39-52.

Carlino, P. (2012). Helping doctoral students of education to face writing and emotional challenges in identity transition. In M. Castelló \& C. Donahue (Eds.), University writing: Selves and texts in academic societies (pp.217-134). Brill.

Castelló, M., Bañales, G., Iñesta, A., \& Vega, N. (2009a). Writing academic texts: organization and structure, authorial voice and intertextuality. http://www.sinte.es/joomla cast/index.php?option=com content\&task=view\&id=22\&I temid $=47$. 
Castelló, M., Iñesta, A., \& Monereo, C. (2009b). Towards self-regulated academic writing: an exploratory study with graduate students in a situated learning environment. Electronic Journal of Research in Educational Psychology, 7(3), 1107-1130.

Castelló, M., \& Donahue, C. (Eds.) (2012). University writing: Selves and texts in academic societies, Vol.24: Brill.doi.org/10.1163/9781780523873

Castelló, M., Iñesta, A., \& Corcelles, M. (2013). Learning to write a research article: Ph. D. students' transitions toward disciplinary writing regulation. Research in the Teaching of English, 442-477.

Castelló, M., McAlpine, L., \& Pyhältö, K. (2017). Spanish and UK post-PhD researchers: Writing perceptions, well-being and productivity. Higher Education Research \& Development, 36(6), 1108-1122.

Cerrato-Lara, M., Castelló, M., Garcia Velazquez, R., \& Lonka, K. (2017). Validation of the writing process questionnaire in two Hispanic populations. Journal of Writing Research, 9(2), 151-171.

Conn, V. S., Ward, S., Herrick, L., Topp, R., Alexander, G. L., Anderson, C. M.,...Georgesen, S. (2015). Managing opportunities and challenges of co-authorship. Western Journal of Nursing Research, 37(2), 134-163.

Cotterall, S. (2011). Doctoral students writing: where's the pedagogy? Teaching in Higher Education, 16(4), 413-425.

Cutas, D., \& Shaw, D. (2015). Writers blocked: On the wrongs of research co-authorship and some possible strategies for improvement. Science and engineering ethics, 21(5), 1315 1329.

Dressen-Hammouda, D. (2008). From novice to disciplinary expert: Disciplinary identity and genre mastery. English for Specific purposes, 27(2), 233-252.

East, J. (2010). Judging plagiarism: A problem of morality and convention. Higher Education 59, 69-83. https://doi.org/10.1007/s10734-009-9234-9

Emerson, L. (2012). The life cycle of the scientific writer: An investigation of the senior academic scientist as writer in Australasian universities. In C. Bazerman, C. Dean, J. Early, K.Lunsford, S. Null, P. Rogers\& A. Stansell (Eds.), International advances in writing research: Cultures, places, measures. Perspectives on writing (pp.355-420).The WAC Clearinghouse; Parlor Press. 
Finnish National Board on Research Integrity (2018). Agreeing on authorship. Recommendation for research publications. https://www.tenk.fi/en/tenkguidelines.(accessed 24/06/2019).

Florence, M. K., \& Yore, L. D. (2004). Learning to write like a scientist: Co-authoring as an enculturation task. Journal of Research in Science Teaching, 41(6), 637-668.

Gallego, L., Castelló, M., \& Badia, A. (2016). Faculty feelings as writers: Relationship with writing genres, perceived competences, and values associated to writing. Higher Education, 71(5), 719-734.

González-Ocampo, G., \& Castelló, M. (2018).Writing in doctoral programs: Examining supervisors' perspectives. Higher Education, 76(3), 387-401.

Guerin, C., Walker, R., Aitchison, C., Mattarozzi Laming, M., Chatterjee Padmanabhan, M., \& James, B. (2017). Doctoral supervisor development in Australian universities: Preparing research supervisors to teach writing. Journal of Academic Language \&Learning, 11(1), 88-103.

Hakkarainen, K., Hytönen, K., Lonka, K., \& Makkonen, J. (2014). How does collaborative authoring in doctoral programs socially shape practices of academic excellence? Talent Development \& Excellence, 6(1), 11-29.

Hayes, N., \& Introna, L.D. (2005). Cultural values, plagiarism, and fairness: When plagiarism gets in the way of learning. Ethics \&Behavior, 15(3), 213-231.

Henriksen, D. (2016). The rise in co-authorship in the social sciences (1980-2013). Scientometrics, 107(2), 455-476.

ICMJE International Committee of Medical Journal Editors (2018). Recommendations. http://www.icmje.org/recommendations/

Inouye, K., \& McAlpine, L. (2019). Developing academic identity: A review of the literature on doctoral writing and feedback. International Journal of Doctoral Studies, 14, 1-31. https://doi.org/10.28945/4168

Iñesta, A., \& Castelló, M. (2012). Towards an integrative unit of analysis: Regulation Episodes in expert research article writing. In C. Bazerman, C. Dean, J. Early, K. Lunsford, S. Null, P. Rogers, \& A. Stansell (Eds.), International advances in writing research: Cultures, places, measures. Perspectives on Writing (pp.421-448). The WAC Clearinghouse; Parlor Press.

Ivanic, R. (2005). The discoursal construction of writer identity. In R. Beach, J. Green, M. Kamil \& T. Shanahan (Eds.), Multidisciplinary perspectives on literacy research (pp.391-416). Hampton Press. 
James, N., \& Lokhtina, I. (2018). Feeling on the periphery? The challenge of supporting academic development and identity through communities of practice. Studies in the Education of Adults, 50(1), 39-56.

Johansen, B. T., Olsen, R. M., Øverby, N.C., Garred, R., \& Enoksen, E. (2019). Team supervision of doctoral students: A qualitative inquiry. International Journal of Doctoral Studies, 14, 69-84.doi.org/10.28945/4177.

Kamler, B. (2008). Rethinking doctoral publication practices: Writing from and beyond the thesis. Studies in Higher Education, 33(3), 283-294.

Kamler, B., \& Thomson, P. (2014). Helping doctoral students write: Pedagogies for supervision. Routledge.

Kitchener, K. S. (1985). Ethical principles and ethical decisions in student affairs. In H. J. Canon \& R. D. Brown (Eds.) New directions for student services: Applied ethics in student services (pp. 17-29). Jossey-Bass.

Kruse, O., Chitez, M., Rodriguez, B., \& Castelló, M. (2016). Exploring European writing cultures. Country reports on genres, writing practices and languages used in European higher education. Winterthur: ZHAW. https://core.ac.uk/download/pdf/55329646.pdf.

Leane, E., Fletcher, L., \& Garg, S. (2019). Co-authorship trends in English literary studies, 1995-2015. Studies in Higher Education,44(4), 786-798.

Lee, A., \& Murray, R. (2015). Supervising writing: Helping postgraduate students develop as researchers. Innovations in Education and Teaching International, 52(5), 558-570.

Löfström, E., Huotari, E., \& Kupila, P. (2017). Conceptions of plagiarism and problems in academic writing in a changing landscape of external regulation. Journal of Academic Ethics, 15(3), 277-292.

Löfström, E. \& Pyhältö, K. (2012). The supervisory relationship as an arena for ethical problem-solving. Education Research International, article ID961505, 1-12.

Löfström, E. \& Pyhältö, K. (2014). Ethical issues in Doctoral supervision - The perspectives of $\mathrm{PhD}$ students in the natural and behavioural sciences. Ethics \& Behavior, 24(3), 195 214.

Löfström, E., \& Pyhältö, K. (2015). “I don't even have time to be their friend!” Ethical dilemmas in $\mathrm{PhD}$ supervision in hard sciences. International Journal of Science Education, 37(16), 2721-2739.

Löfström, E., Trotman, T., Furnari, M., \& Shephard, K. (2015). Who teaches academic integrity and how do they do it? Higher Education, 69(3), 435-448. 
Lokhtina, I. (2018). Gaining legitimacy: Mentoring as an avenue to navigate the transition into a new academic workplace. Journal for the Study of Education and Development/Infancia y Aprendizaje, 41(3), 581-618.

Lonka, K., Chow, A., Keskinen, J., Hakkarainen, K., Sandström, N., \& Pyhältö, K. (2014). How to measure $\mathrm{PhD}$. students' conceptions of academic writing-and are they related to well-being? Journal of Writing Research, 5(3), 245-269.

Macfarlane, B. (2017). The ethics of multiple authorship: Power, performativity and the gift economy. Studies in Higher Education, 42(7), 1194-1210.

Maher, M. A., Feldon, D. F., Timmerman, B. E., \& Chao, J. (2014). Faculty perceptions of common challenges encountered by novice doctoral writers. Higher Education research and Development, 33(4), 699-711.

McAlpine, L. \& Amundsen, C. (2009). Identity and agency: Pleasures and collegiality among the challenges of the doctoral journey. Studies in Continuing Education, 32(2), July 2009, 109-125.

McGrail, M. R., Rickard, C. M., \& Jones, R. (2006).Publish or perish: A systematic review of interventions to increase academic publication rates. Higher Education Research and Development, 25(1), 19-35.

Nelson, N., \& Castelló, M. (2012). Academic writing and authorial voice. In M. Castelló \& C. Donahue (Eds.). University writing: Selves and texts in academic societies (pp.3351). Brill.

Paré A. (2011). Speaking of writing: Supervisory feedback and the dissertation. In L. McAlpine, \& C. Amundsen (Eds.), Doctoral education: Research-based strategies for doctoral students, supervisors and administrators (pp.59-74). Springer.

Pecorari, D. (2003).Good and original: Plagiarism and patchwriting in academic second language writing. Journal of Second Language Writing, 12(4), 317-345.

Prior, P. (2013). Writing/disciplinarity: A sociohistoric account of literate activity in the academy. Routledge.

Russell, D. (1997). Rethinking genre in school and society: an activity theory analysis. Written communication. Sage Journals, 14(4), 504-554.

Selbach, H. V., Motta-Roth, D., \& Schmidt, A. P. C. (2018). Academic Literacies: Appraisal and social sanction about authorship and scientific integrity. Revista Brasileira de Linguística Aplicada[online], 18(4),703-736.

Smith, E. A. (2017). Theoretical foundation for the ethical distribution of authorship in multidisciplinary publications. Kennedy Inst. Ethics J., 27, 371-411. 
Swales, M. A. (2009). Dialectical behaviour therapy: Description, research and future directions. International Journal of Behavioral Consultation and Therapy, 5, 164-177.

Tardy, C. (2003). Genre system view of the funding of academic research. Written communication, 20(1), 7-36. doi.org/10.1177/0741088303253569

Valentine, K. (2006). Plagiarism as literacy practice: Recognizing and rethinking ethical binaries. College Composition and Communication, 58(1), 89-109. 